\title{
Aplicação didática inclusiva no ensino de Química para um aluno surdo
}

\author{
Inclusive didatic application in teaching Chemistry for a deaf student \\ Aplicación didáctica inclusiva en la enseñanza de la Química para un estudiante sordo
}

Recebido: 26/05/2021 | Revisado: 04/06/2021 | Aceito: 07/06/2021 | Publicado: 22/06/2021

Rita de Cássia Ramos Queiroz de Freitas ORCID: https://orcid.org/0000-0002-3931-7975 Instituto Federal de Educação, Ciência e Tecnologia Baiano, Brasil E-mail: 20190000723@alunos.ifbaiano.edu.br

Mário Sérgio de Oliveira Paz

ORCID: https://orcid.org/0000-0003-3086-6932 Instituto Federal de Educação, Ciência e Tecnologia do Pará, Brasil E-mail: mario.paz@ifpa.edu.br

\begin{abstract}
Resumo
As propostas didáticas que oferecem suporte ao conhecimento químico pautados no uso da Língua Brasileira de Sinais (Libras) são relevantes para o processo de aprendizagem de alunos surdos. Diante disso, o objetivo deste trabalho foi potencializar a compreensão do conteúdo sobre "Identificação das Funções Inorgânicas: Ácidos e Bases" para uma aluna surda do $1^{\circ}$ ano do ensino médio do Instituto Federal Baiano, campus Guanambi, aplicando uma estratégia didática inclusiva com materiais do cotidiano escolar. A intervenção metodológica foi desenvolvida em três encontros semanais com duração de uma hora e meia. Os materiais utilizados no recurso didático foram: clipes coloridos e fichas de papel com informações referentes ao conteúdo de química supracitado associado ao sinalário em Libras. Os resultados mostraram um progresso de $90 \%$ em relação ao desempenho da discente nas atividades do tema abordado após a ação inclusiva. Assim, a mediação pedagógica proporcionou a melhoria na assimilação do assunto de química para a estudante.
\end{abstract}

Palavras-chave: Ensino de química; Estratégia inclusiva; Surdo.

\begin{abstract}
The didactic proposals that support chemical knowledge based on the use of the Brazilian Sign Language (Libras) are relevant to the learning process of deaf students. Therefore, the objective of this work was to enhance the understanding of the content on "Identification of Inorganic Functions: Acids and Bases for a deaf student in the 1st year of high school at the Federal Institute of Bahia, Guanambi campus, applying an inclusive didactic strategy with everyday school materials. The methodological intervention was developed in three weekly meetings lasting one and a half hours.The materials used in the didactic resource were: colored clips and paper sheets with information regarding the aforementioned chemical content associated with the sign in Libras. The results showed a 90\% progress in relation to the student's performance in the activities of the theme addressed after the inclusive action. Thus, pedagogical mediation provided an improvement in the assimilation of the subject of chemistry for the student.
\end{abstract}

Keywords: Chemistry teaching; Inclusive strategy; Deaf.

\section{Resumen}

Las propuestas didácticas que apoyan el conocimiento químico basado en el uso de la Lengua de Signos Brasileña (Libras) son relevantes para el proceso de aprendizaje de los estudiantes sordos. Por lo tanto, el objetivo de este trabajo fue profundizar la comprensión del contenido sobre "Identificación de Funciones Inorgánicas: Ácidos y Bases" para un estudiante sordo de 1er año de secundaria en el Instituto Federal de Bahía, campus Guanambi, aplicando una estrategia didáctica con materiales cotidianos de la vida escolar. La intervención metodológica se desarrolló en tres reuniones semanales de una hora y media. Los materiales utilizados en el recurso didáctico fueron: clips de colores y hojas de papel con información sobre el contenido químico antes mencionado asociado al signo en Libras. Los resultados mostraron un avance del $90 \%$ en relación al desempeño del alumno en las actividades del tema abordado luego de la acción inclusiva. Así, la mediación pedagógica supuso una mejora en la asimilación de la asignatura de química por parte del alumno.

Palabras clave: Enseñanza de la química; Estrategia inclusiva; Sordo.

\section{Introdução}

Durante muito tempo as pessoas com deficiências foram consideradas incapazes de adquirir qualquer tipo de conhecimento (Schmidt, 2011). No Brasil, o processo de inclusão educacional foi inspirado no modelo europeu e americano 
baseado na combinação de práticas assistencialistas e no apoio de instituições filantrópicas e privadas (Mazzota, 1996, apud Mendes \& Reis, 2021).

Diante da perspectiva da educação inclusiva, a Constituição Federal Brasileira, em 1946, estabeleceu a obrigatoriedade do atendimento educacional especializado aos alunos com deficiências (Mendes \& Reis, 2021). Nos anos 90, a Conferência Mundial de Educação para Todos, na Tailândia, torna evidente a educação como um direito de todos (Pereira, et al., 2018a). Quatro anos depois, a Declaração de Salamanca na Espanha potencializou o direito à educação nas escolas, independente da deficiência (UNESCO, 1994). A Lei de Diretrizes e Bases da Educação Nacional No 9.394/96, de 20 de dezembro de 1996, também reforçou a garantia desse tipo de educação gratuitamente (Brasil, 1996). Ademais, o documento promulgado pela Política Nacional de Educação Especial na Perspectiva da Educação Inclusiva destacou a importância da elaboração e organização de recursos pedagógicos que possibilitem a completa participação dos discentes, considerando suas especificidades (Brasil, 2008). Para Sanches e Teodoro (2006) a inclusão deve trazer mudanças significativas na mentalidade, na política e nas estratégias didáticas possibilitando a autonomia e independência do estudante no âmbito escolar e social.

A inclusão dos surdos no sistema educacional brasileiro é garantida pela utilização da Língua Brasileira de Sinais (Libras), através da Lei $\mathrm{N}^{\circ}$ 10.436, de 24 de abril de 2002, regulamentada pelo Decreto $\mathrm{N}^{\circ}$ 5.626, de 22 de dezembro de 2005 (Brasil, 2005). De acordo com essa lei, a Libras constitui um sistema linguístico com estrutura gramatical própria, permitindo a comunicação, a informação e a educação dos deficientes auditivos por meio de experiência visual-motora (Brasil, 2002).

Apesar do respaldo legal para a oferta dos serviços de tradutor e intérprete de Libras, equipamentos e tecnologias, como forma de democratização das oportunidades educacionais (Brasil, 2005), detecta-se um grande déficit de aprendizagem dos discentes surdos em diversos conteúdos escolares (Santos, et al., 2015). Lacerda (2006) e Lunardi (2001) apontam que a inclusão educacional para alunos com essa especificidade é uma proposta adequada, porém não necessariamente eficaz, pois se refere em grande parte, apenas ao acesso desses estudantes ao espaço físico da escola. Para Quadros e Schmiedt (2006), esse processo também não pode apresentar como única ferramenta de inclusão a presença do intérprete em sala de aula. Assim, a prática inclusiva com aprendizagem significativa só terá êxito com adequações no processo didático-pedagógico da escola, conforme afirma Domanovski e Meyer (2016).

Neste sentido, é imprescindível um repensar sobre as estratégias de ensino para garantir a assimilação adequada dos conteúdos curriculares pelos estudantes surdos. Para Silveira, et al., (2012) e Sousa e Silveira (2011) existem diferentes formas de ensinar e aprender um mesmo fenômeno, mas é necessário um treinamento formativo para os professores em relação à utilização de alternativas inclusivas e conhecimento básico da Libras. Essa formação torna viável o atendimento educacional especializado, principalmente, quando se aborda assuntos específicos para alunos que muitas vezes ainda estão em processo de aquisição da Libras e concomitantemente aprendendo termos científicos em português (Oliveira \& Benite, 2015a).

O ensino de química na perspectiva de inclusão dos surdos é um desafio, pois essa área apresenta uma linguagem peculiar com carência de simbologia em Libras. Em decorrência disso, os intérpretes nem sempre alcançam uma tradução adequada, ocasionando obstáculos no processo de ensino aprendizagem dos discentes (Stadler, 2019, Sousa \& Silveira, 2011 e Lindino, et al., 2009). Diante disso, a utilização de materiais e mediações pedagógicas considerando a condição linguística do aluno surdo, associadas aos recursos disponíveis na escola e à criatividade no processo de planejamento das aulas podem potencializar a compreensão dos conteúdos das disciplinas básicas, como a Química (Costa, 2018, Alves, et al., 2017, Nichele \& Schlemmer, 2014, Nicola \& Paniz, 2016).

Para Freitas (2007) apud Costa (2018), os materiais didáticos são caracterizados como qualquer recurso utilizado em um procedimento de ensino com a finalidade de estimular o aluno e aproximá-lo do conteúdo. Já as mediações escolares são definidas como uma atitude do professor que se coloca como ponte entre o aluno e a aprendizagem e que ativamente contribui para que o aprendiz chegue aos seus objetivos (Pereira, et al.,2011). Ainda nesse contexto, a Libras e o estímulo visual 
precisam e devem ser considerados como artifícios pedagógicos (Fernandes \& Reis, 2017, Lacerda, 2000). O aspecto lúdico também pode ser inserido para facilitar o reforço de conteúdos, a criatividade e o espírito de cooperação (Rocha, et al., 2019, Silva 2016).

Um estudo realizado por Pinto e Oliveira (2012) apontou que um dos assuntos de química que causa maior dificuldade de aprendizagem para os alunos surdos são as "Funções Inorgânicas". Nessa conjuntura, o objetivo deste trabalho foi aprimorar a compreensão do conteúdo sobre "Identificação das Funções Inorgânicas: Ácidos e Bases", baseado na Teoria de Arrhenius para uma aluna surda do ensino médio, empregando um artifício didático inclusivo com materiais escolares.

\section{Metodologia}

Esta pesquisa é de natureza qualitativa e foi proveniente do desenvolvimento do projeto de ensino "Monitoria acadêmica como instrumento da prática docente no Ensino de Química" realizado no Instituto Federal (IF) Baiano, campus Guanambi. Segundo Pereira, et al., (2018b) este tipo de estudo, em geral, ocorre no ambiente natural com coleta direta de dados e as ações dos envolvidos são focos de atenção para o pesquisador.

A estratégia de ensino inclusiva abordou o assunto "Identificação das Funções Inorgânicas: Ácidos e Bases", segundo a Teoria de Arrhenius, para uma aluna surda do $1^{\circ}$ ano do ensino médio do IF Baiano, campus Guanambi, em três encontros semanais, com duração de uma hora e meia. Os materiais que integraram o artifício pedagógico no processo didático foram: clipes coloridos e papel. O desenvolvimento metodológico deste trabalho envolveu três etapas, conforme apresentado na Figura 1.

Figura 1 - Fluxograma da metodologia empregada.

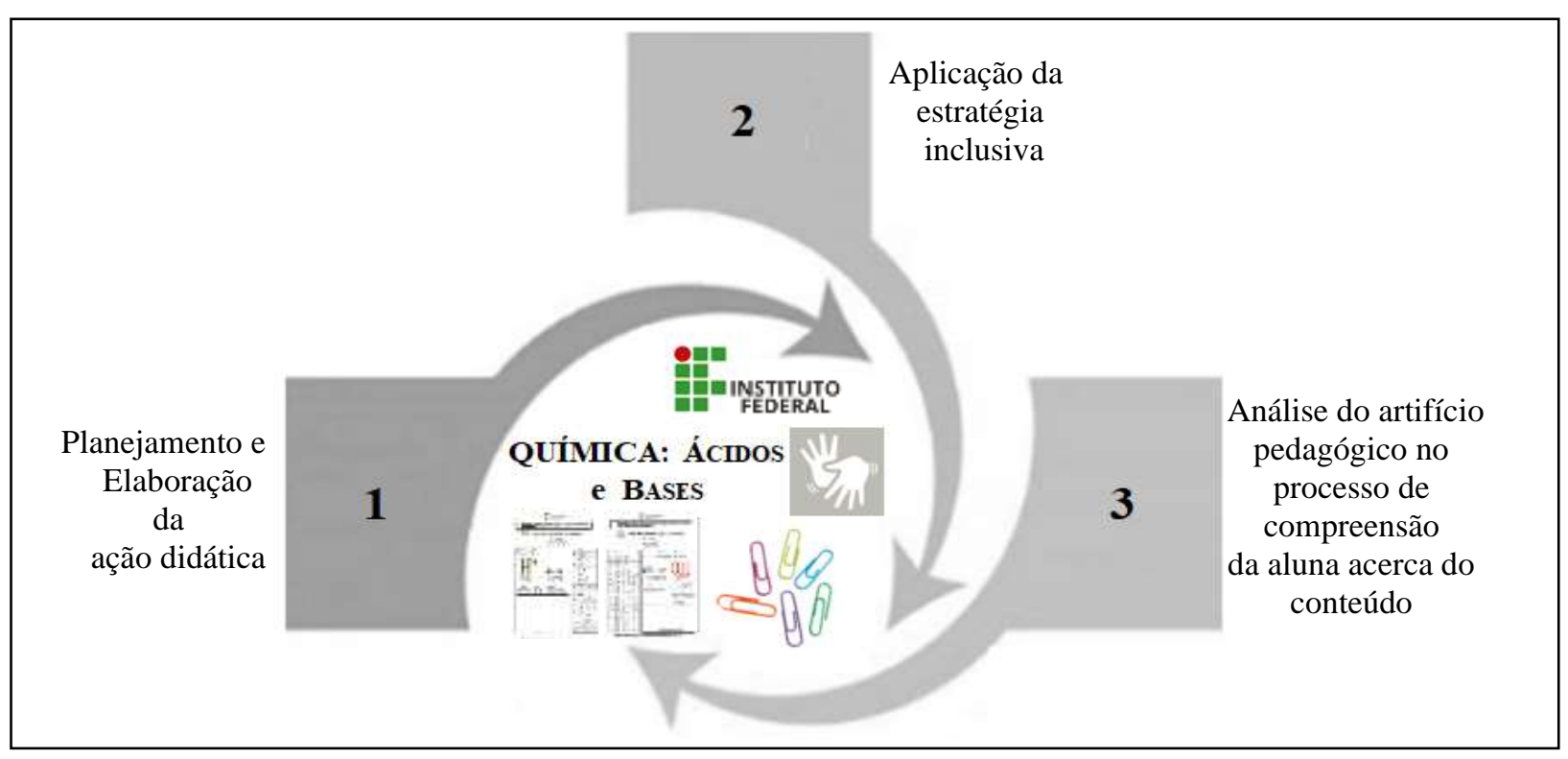

Fonte: Autores (2021).

Reuniões de planejamento foram realizadas para traçar as metas e elaborar a ação didática inclusiva. Foram preparadas fichas, em papel no formato $\mathrm{A}_{4}$ com medidas $297 \times 210 \mathrm{~mm}$, contendo as informações referentes à temática química supramencionada associada com sinalário em Libras (Figuras 2 e 3). 
Figura 2 - Modelo da ficha empregada na execução do artificio didático inclusivo: Identificação de Ácidos.

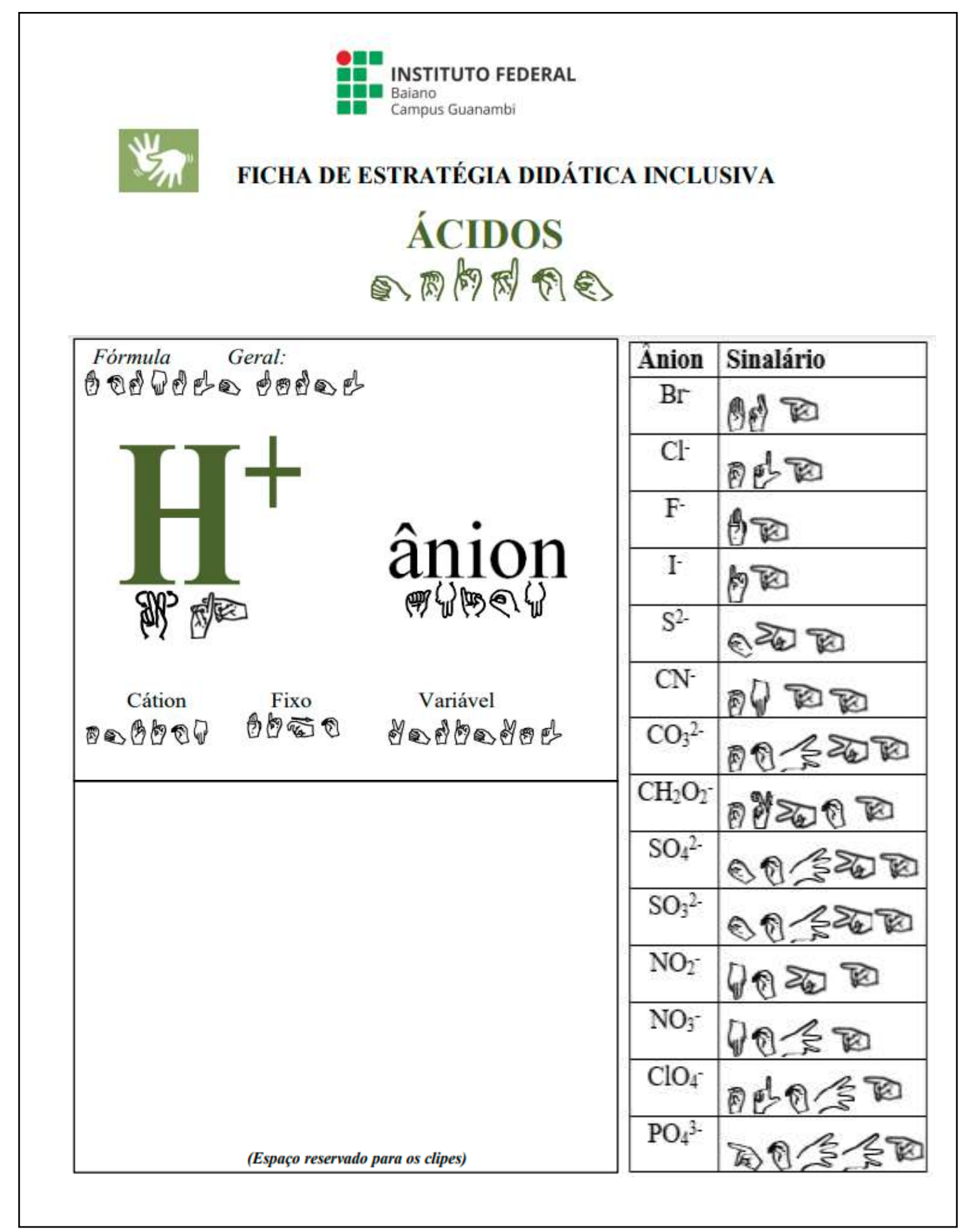

Fonte: Autores (2021). 
Figura 3 - Modelo da ficha empregada na execução do artificio didático inclusivo: Identificação de Bases.

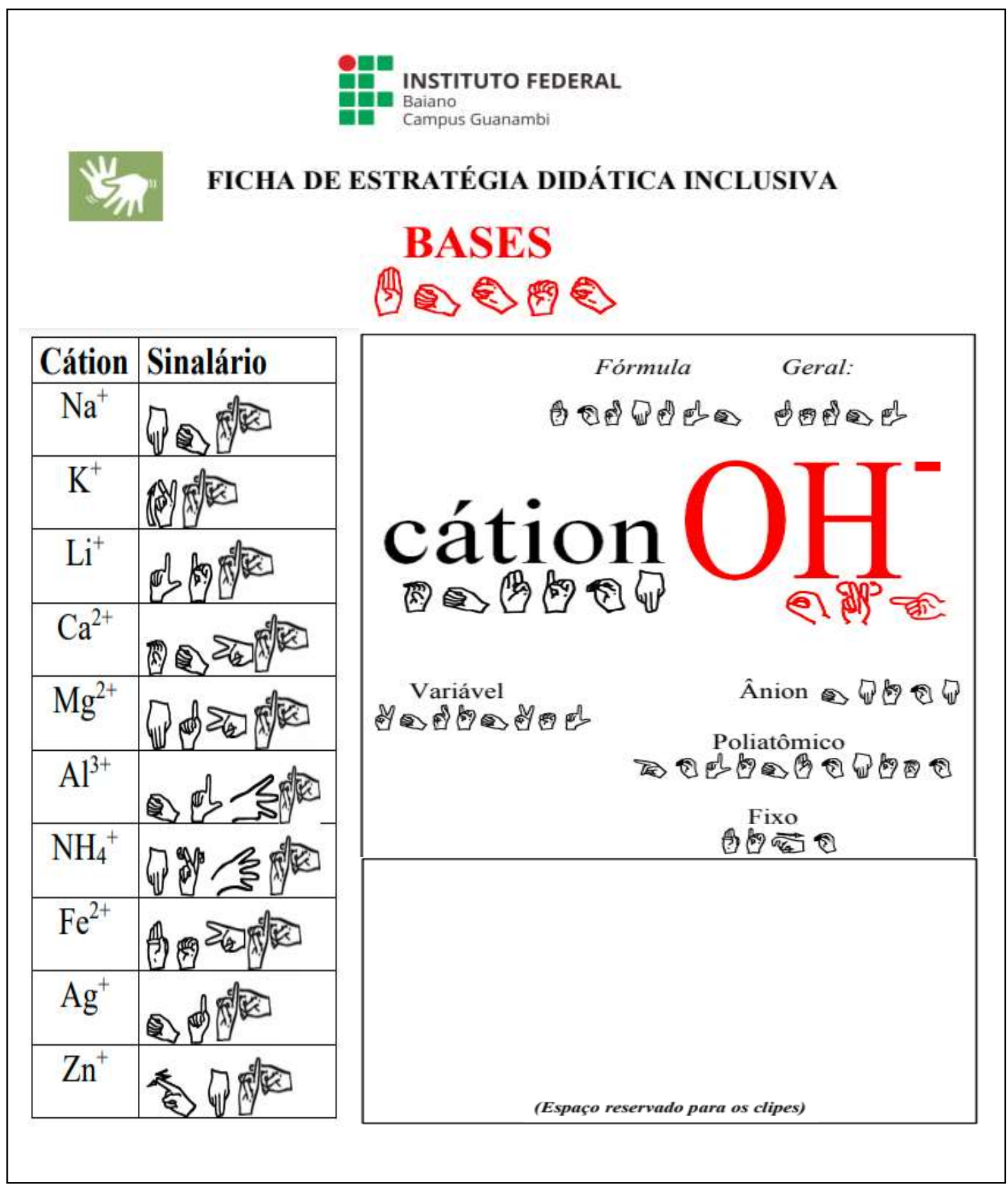

Fonte: Autores (2021).

A proposta didática foi conduzida pela monitora da disciplina de Química, com conhecimento em Libras, e, mediado pelo professor. Essa ação foi baseada na pedagogia visual através de analogias entre os clipes coloridos e as fórmulas moleculares das funções ácidos e bases com o auxílio das fichas modelo (Figuras 2 e 3). Ao término de cada intervenção pedagógica, a aluna foi instruída a resolver as atividades do assunto abordado. Em seguida, foi avaliado o processo de compreensão da discente através da análise comparativa dos resultados obtidos com a resolução das atividades de química antes e depois do artifício didático. 


\section{Resultados e Discussão}

A inclusão de alunos surdos no ensino regular deve acontecer por meio de métodos e recursos educativos adequados, conforme assegurado pela Lei de Diretrizes e Bases da Educação Nacional (Brasil, 1996). Deve contar também com o apoio de um intérprete, responsável pela tradução e interpretação dos conteúdos curriculares para a Língua Brasileira de Sinais (Libras) (Brasil, 2005). Entretanto, é importante mencionar que a presença desse profissional não garante que questões didáticas sejam atendidas, visto que este não assume o papel do professor no processo de ensino e aprendizagem desses discentes (Gonçalves \& Festa, 2013).

Sob a ótica inclusiva do ensino de química, Ferreira, et al., (2014a) e Pereira, et al., (2011) apontam que as barreiras potenciais nesse processo são provenientes da linguagem particular dessa disciplina associada à carência de terminologias químicas em Libras e da escassez de práticas pedagógicas redirecionadas. Apesar dessas dificuldades, é importante ressaltar que a utilização de mediações didáticas amparadas por recursos multimodais e imagéticos, que contextualizem o conhecimento químico à Libras, contribuem de forma eficaz na assimilação dos conteúdos dessa disciplina para os educandos surdos (Fernandes \& Reis, 2017, Gomes, et al., 2015, Pereira et al., 2011). Assim, essas estratégias induzem formas particulares de desenvolvimento do aluno com essa especificidade promovendo mudanças cognitivas que favorecem a aprendizagem (Pereira et al., 2011).

No início deste estudo a aluna manifestou uma dificuldade em identificar as funções inorgânicas: Ácidos e Bases, apresentando um baixo rendimento na resolução das atividades desse conteúdo. Segundo Oliveira \& Benite, (2015b), Benite, et al., (2008) apud Pereira, et al., (2011) os problemas de apropriação do conhecimento pelos surdos se estabelecem porque ainda predominam as metodologias tradicionais em sala de aula. Além disso, os conceitos químicos são essencialmente simbólicos para os quais é ínfimo a correspondência na Libras (Pereira, et al., 2011). Para esses autores os problemas de compreensão do aluno surdo podem ser minimizados quando a linguagem oral é auxiliada por meio de recursos que estimulem outros sentidos, sendo a visão o que apresenta maior possibilidade de retenção de informações. Diante desse contexto, os pesquisadores deste trabalho elaboraram uma prática pedagógica inclusiva com estímulo visual e lúdico que reconfigurou o método didático abordado em sala de aula permitindo a melhoria da compreensão da discente sobre as funções inorgânicas supracitadas. A figura 4 mostra a dinâmica realizada com o emprego da estratégia inclusiva.

Figura 4 - Aplicação do recurso didático - (A): Identificação de Ácidos e (B): Identificação de Bases.

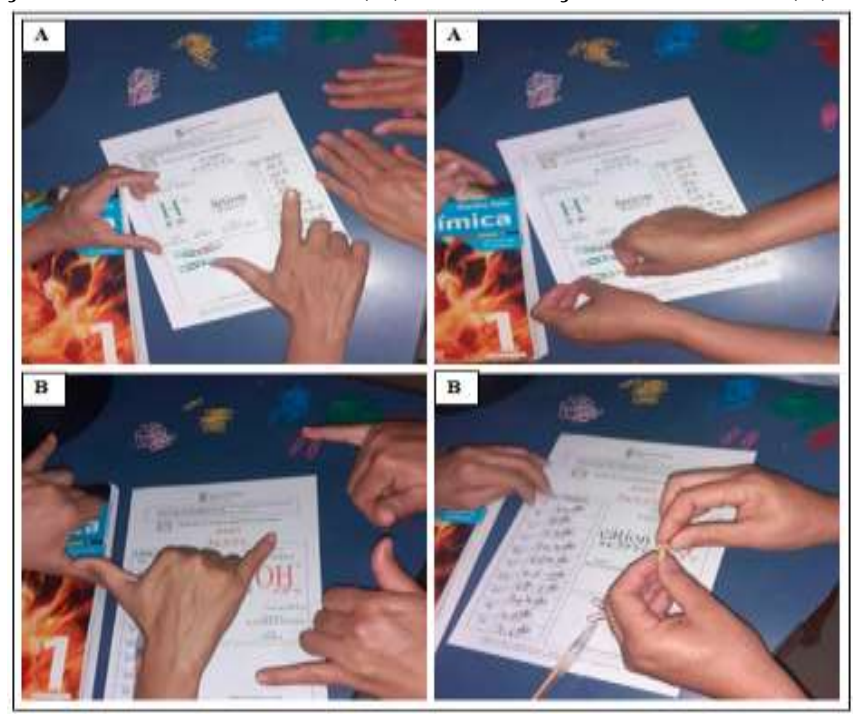

Fonte: Autores (2021). 
A intervenção empregada com foco lúdico e comparativo, através do uso clipes coloridos relacionados às fórmulas moleculares das funções químicas, permitiu a discente assimilar a ideia que o cátion de um ácido é fixo, ou seja, será sempre o íon $\mathrm{H}^{+}$, e, na base a parte fixa da fórmula é o ânion poliatômico, hidroxila $\left(\mathrm{OH}^{-}\right)$, tomando como base a Teoria de Arrhenius. Isso foi observado quando a estudante foi instruída a representar com clipes as fórmulas de diversos ácidos e bases, sendo auxiliada pelo sistema de datilologia provenientes do estudo de Capovilla e Raphael (2001) presentes nas fichas modelo (Figura 2 e 3). Para Costa e Nicolli (2017) esse sistema, em que se representam as letras dos alfabetos da língua oral escrita por meio das mãos, é uma alternativa que facilita o entendimento dos conteúdos para os discentes surdos. Nesse sentido, as fichas mencionadas privilegiaram a representação visual e proporcionaram a acessibilidade para internalização dos conceitos químicos, atendendo as peculiaridades da identidade surda.

Após a mediação pedagógica, a estudante respondeu novamente os exercícios desse assunto obtendo um progresso significativo no processo de compreensão, conforme apresentado na Figura 5.

Figura 5 - Rendimento da aluna surda antes e após aplicação da estratégia didática.

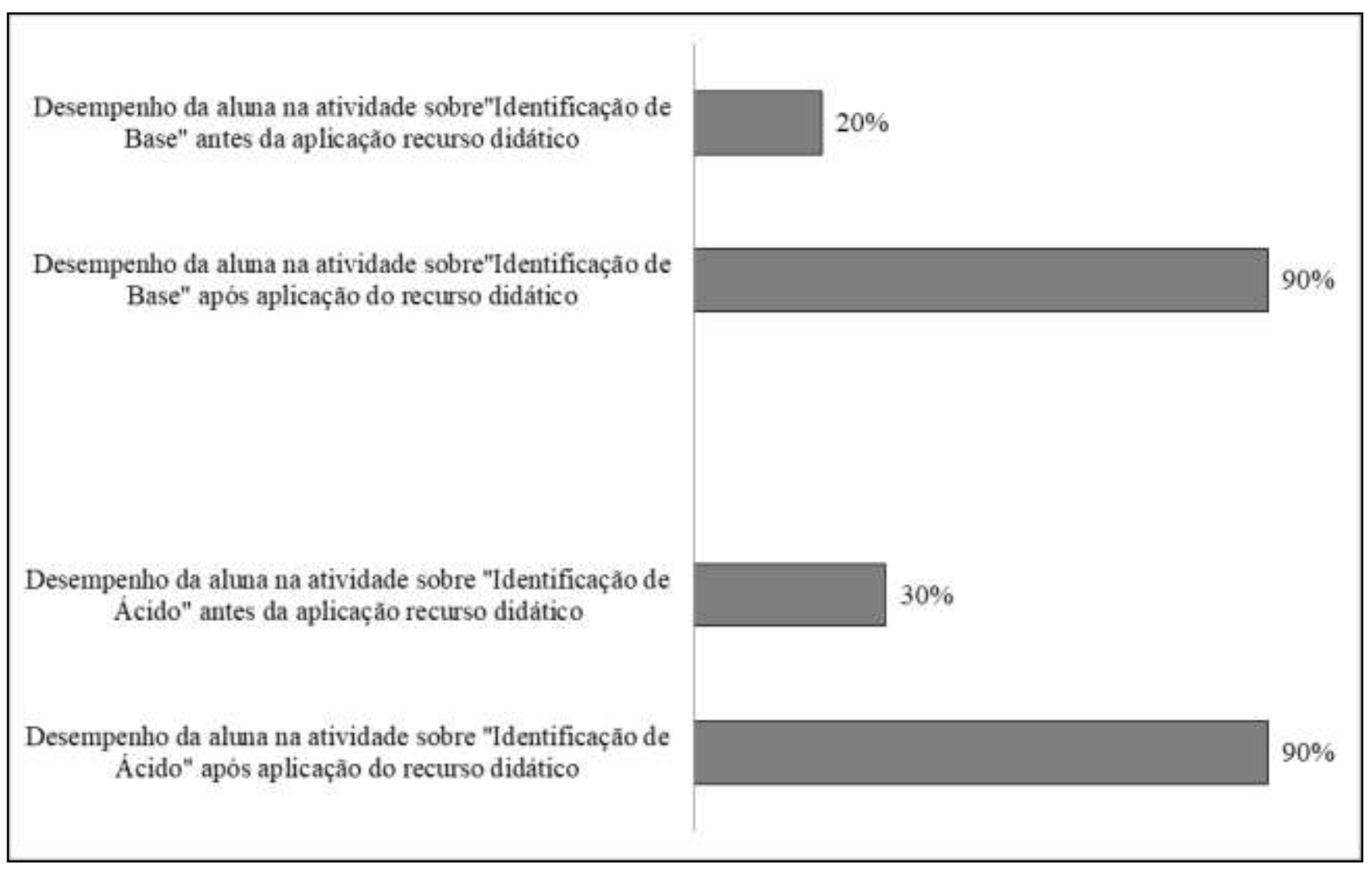

Fonte: Autores (2021).

A melhoria do rendimento da aluna observado na Figura 5 pode ser relacionada ao caráter lúdico da ação inclusiva com estímulo visual. Segundo Silva e Delfino (2016) a utilização da ludicidade no ensino de Química tem demonstrado grande eficiência na inclusão e contribui para atrair a atenção do aluno e melhorar a assimilação dos conteúdos. Para Fernandes e Reis (2017) a experiência ocular funciona como uma alternativa que amplia o processo de aprendizagem pelos deficientes auditivos, pois esses usam uma língua de modalidade gesto-visual para se comunicar. Assim, é fundamental que a aprendizagem desses alunos envolva atividades visuais, de forma a fazer com que esses possam ler imagens e delas extrair significados de modo interdependente à constituição do pensamento (Pereira, et al., 2011). 
O resultado dessa pesquisa corrobora com os estudos de Rocha, et al., (2019), Fernandes e Reis (2017), Ferreira e Nascimento (2014b) que utilizaram recursos pedagógicos inclusivos para aprimorar a aprendizagem de conteúdos da disciplina de química. Portanto, a execução do artifício pedagógico garantiu a participação da aluna, que demonstrou empolgação em todos os encontros, e, promoveu uma socialização e troca de conhecimento através da argumentação.

\section{Considerações Finais}

A estratégia didática promoveu a inclusão e potencializou a compreensão, assimilação e estímulo da aluna surda do Instituto Federal Baiano - campus Guanambi em relação a "Identificação das Funções Inorgânicas: Ácido e Base" de acordo com a Teoria de Arrhenius. A melhoria do rendimento dessa discente quanto ao conteúdo de química supramencionado foi proveniente dessa mediação interativa caracterizada pelos aspectos de ludicidade, estímulo visual e o sistema de datilologia. Além disso, a ação didática foi valiosa para o processo de formação docente da monitora da disciplina de química.

$\mathrm{O}$ processo de inclusão dos surdos é um dos compromissos das Instituições de Ensino para promover a democratização do sistema educacional e um clima de pertencimento maior à escola por parte dos estudantes com essa especificidade. Como propostas para trabalhos futuros, sugere-se realizar um levantamento local para saber quais os outros assuntos da disciplina de química causam maiores dificuldades no processo de aprendizagem dos estudantes com surdez, e, elaborar outras estratégias didáticas inclusivas que aprimorem o ensino de química para esses alunos.

\section{Agradecimentos}

Ao Instituto Federal (IF) Baiano - Campus Guanambi onde foi desenvolvido o projeto de ensino: "Monitoria acadêmica como instrumento da prática docente no ensino de química”, coordenado pelo Professor Mário Paz em 2019.

Ao Núcleo de Atendimento às Pessoas com Necessidades Específicas (NAPNE) do IF Baiano - Campus Guanambi pelo apoio ao trabalho.

Ao Grupo de Pesquisa Multidisciplinar em Ensino, Educação, Química, Linguagens e Meio Ambiente do Instituto Federal do Pará - Campus Paragominas no qual faz parte o docente que orientou este estudo.

\section{Referências}

Alves, M. D. F., Pereira, G. V. \& Viana, M. A. P. (2017). Tecnologia assistiva na perspectiva de educação inclusiva: o ciberespaço como lócus de autonomia e autoria. Laplage em Revista. 3 (2), 159-169. https://www.redalyc.org/jatsRepo/5527/552756522014/html/index.html

Brasil, (1996). Ministério da Educação. Lei de Diretrizes e Bases da Educação Nacional. Lei $n^{\circ} 9.394$ de 20 de dezembro de 1996. Estabelece as diretrizes e bases da educação nacional. Brasília. http://portal.mec.gov.br/seesp/arquivos/pdf/lei9394_1dbn1.pdf

Brasil. (2002). Ministério da Educação. Lei $N^{\circ}$ 10.436, de 24 de abril de 2002. Dispõe sobre a Língua Brasileira de Sinais. http://www.planalto.gov.br/ccivil_03/leis/2002/110436.htm

Brasil. (2005). Ministério da Educação. Decreto $N^{\circ}$ 5626, de 22 de dezembro de 2005. Regulamenta a Lei $\mathrm{N}^{\circ} 10.436$, de 24 de abril de 2002. http://www.planalto.gov.br/ccivil_03/leis/2002/110436.htm

Brasil. (2008). Ministério da Educação. Política Nacional de Educação Especial na Perspectiva da Educação Inclusiva. MEC.

http://portal.mec.gov.br/arquivos/pdf/politicaeducespecial.pdf

Capovilla, F. C., \& Raphael, W. D. (2001). Dicionário Enciclopédico Ilustrado Trilíngue da Língua Brasileira de Sinais. Volumes I e II. São Paulo: EDUSP, FABESP, Fundação Vitae, FENEIS, Brasil Telecom.

Costa, J. S., \& Nicolli, A. A. (2017). Ensino de Química \& Surdez: Percepções, Reflexões e Implicações do Processo de Inclusão. XI Encontro Nacional de Pesquisa em Educação em Ciências - XI ENPEC Universidade Federal de Santa Catarina. Ensino e aprendizagem de conceitos e processos científicos. http://www.abrapecnet.org.br/enpec/xi-enpec/anais/resumos/R0653-1.pdf

Costa, L. da. (2018). Adaptação de materiais/recursos na educação de surdos: uma revisão bibliográfica. Comunicações, 25 (3), $293-320$. http://dx.doi.org/10.15600/2238-121X/comunicacoes.v25n3p293-320

Domanovski, M., \& Meyer, V. A. (2016). A importância da libras para inclusão escolar do surdo. Cadernos PDE do Estado no Paraná, 1, 1-16. http://www.diaadiaeducacao.pr.gov.br/portals/cadernospde/pdebusca/producoes_pde/2016/2016_pdp_edespecial_unicentro_marilenedomanovski.pdf 
Fernandes, J. M., \& Reis, I. F. (2017). Estratégia Didática Inclusiva a Alunos Surdos para o Ensino dos Conceitos de Balanceamento de Equações Químicas e de Estequiometria para o Ensino Médio. Química Nova na Escola, 39 (2), 186-194. http://dx.doi.org/10.21577/0104-8899.20160075

Ferreira, W. M., Nascimento, S. P. F., \& Pitanga, A. F. (2014a). Dez Anos da Lei da Libras: Um Conspecto dos Estudos Publicados nos Últimos 10 Anos nos Anais das Reuniões da Sociedade Brasileira de Química. Química Nova na Escola, 36 (3), p.185-193. http://qnesc.sbq.org.br/online/qnesc36_3/05-EA-3613.pdf

Ferreira, W. M., \& Nascimento, S. P. de. F. (2014b). Utilização do jogo de tabuleiro - ludo - no processo de avaliação da aprendizagem de alunos surdos. Química Nova na Escola, 36 (1), 28-36. http://dx.doi.org/10.5935/0104-8899.20140004

Gomes, E. A.; Souza, V. C. A.; \& Soares, C. P. (2015). Articulação do conhecimento em museus de Ciências na busca por incluir estudantes surdos: analisando as possibilidades para se contemplar a diversidade em espaços não formais de educação. Experiências em Ensino de Ciências, 10 (1), 81-97. https://if.ufmt.br/eenci/artigos/Artigo_ID266/v10_n1_a2015.pdf

Gonçalves, H. B., \& Festa, P. S. V. (2013). Metodologia do professor no ensino de alunos surdos. Revista Eletrônica do Curso de Pedagogia das Faculdades OPET, 1-13. http://www.opet.com.br/faculdade/revista-pedagogia/pdf/n6/ARTIGO-PRISCILA.pdf

Lacerda, C. B. F. (2000) A prática pedagógica mediada (também) pela língua de sinais: trabalhando com sujeitos surdos. Caderno Cedes. 20 (50), $70-83$. https://www.scielo.br/pdf/ccedes/v20n50/a06v2050.pdf

Lacerda. C. B. F. de. (2006). A inclusão escolar de alunos surdos: o que dizem alunos, professores e intérpretes sobre esta experiência. Caderno Cedes. 26(69), 163-184. https://www.scielo.br/pdf/ccedes/v26n69/a04v2669.pdf

Lindino, T. C., Lindino, C. A., Steinbach, G. M., \& Oliveira, C. (2009). Química para discentes surdos: uma linguagem peculiar. Revista Trama. 5(10), 145158. https://doi.org/10.48075/rt.v5i10.4423

Lunardi, M. L. (2001). Inclusão/exclusão: duas faces da mesma moeda. Revista Educação Especial. (18), $27-35$. https://periodicos.ufsm.br/educacaoespecial/article/view/5181/3176

Mendes, L. C. \& Reis, D, A. dos. (2021). Políticas públicas de educação inclusiva no Brasil e na Bahia: avanços e recuos. Research, Society and Development. 10 (3), 1-10. http://dx.doi.org/10.33448/rsd-v10i3.12989

Nichele, A.G. \& Schlemmer, E. (2014). Aplicativos para o ensino e aprendizagem de Química. Revista Novas tecnologias na Educação. 12(2), 1-12. https://seer.ufrgs.br/renote/article/view/53497/33014

Nicola, J. A., \& Paniz, C. M. (2016). A importância da utilização de diferentes recursos didáticos no ensino de biologia. Revista do Núcleo de Educação a distância da Unesp. 2 (1), 355-381. file:///C:/Users/andre/Downloads/373-1202-1-PB.pdf

Oliveira, W. D., \& Benite, A. M. C. (2015a). Estudos sobre a relação entre o intérprete de LIBRAS e o professor: implicações para o ensino de ciências. Revista Brasileira de Pesquisa em Educação em Ciências. 15 (3), 597-626. https://periodicos.ufmg.br/index.php/rbpec/article/view/4331/2897

Oliveira, W. D. de., \& Benite, A. M. C. (2015b). Aulas de ciências para surdos: estudos sobre a produção do discurso de intérpretes de LIBRAS e professores de ciências. Ciência \& Educação. 21 (2), 457-472. http://dx.doi.org/10.1590/1516-731320150020012

Pereira, A. dos. R., Pereira, M. R., Virgens, K. L., \& Ribeiro, S. D. (2018a). Formação dos professores de ciências naturais: reflexões sobre inclusão escolar. Brazilian Applied Science Review. 2(2), 697-711. file:///C:/Users/andre/Downloads/441-1195-1-PB\%20(1).pdf

Pereira, A.S., Shitsuka, D. M., Parreira, F. J., \& Shitsuka, R. (2018b). Metodologia da pesquisa científica. Santa Maria, UFSM.

Pereira, L. de. L. S., Benite, C. R. M., \& Benite, A. M. C. (2011). Aula de química e surdez: sobre interações pedagógicas mediadas pela visão. Química nova na escola, 33 (1), 47- 56.https://files.cercomp.ufg.br/weby/up/426/o/Aula_de_Qu\%C3\%ADmica_e_Surdez_sobre_intera\%C3\% A7\%C3\%B5es_pe dag\%C3\%B3 gicas_mediadas_pela_vis\%C3\%A3o.pdf?1357732844

Pinto, E.S. da.S., \& Oliveira, A.C.G.de. (2012). Ensino de Química para surdos na perspectiva de alunos surdos, professor, intérprete e coordenação. Divisão de Ensino de Química da Sociedade Brasileira de Química (ED/SBQ) UFBA, UESB, UESC e UNEB. Ensino de Química e Inclusão. file:///C:/Users/andre/Downloads/7518-21711-1-PB\%20(1).pdf

Quadros, R, M., \& Schmiedt, M, L, P. (2006). Ideias para Ensinar Português para Alunos Surdos. Brasília: MEC/SEESP. http://portal.mec.gov.br/seesp/arquivos/pdf/port_surdos.pdf

Rocha, K. N., Almeida, N. M., Soares, C. R. G., \& Silva, L. F. M. S. (2019). Q-LIBRAS: um jogo educacional para estimular alunos surdos à aprendizagem de Química. Revista Educação Especial. 32. http://dx.doi.org/10.5902/1984686X32977

Sanches, I., \& Teodoro, A. (2006). Da integração à inclusão escolar: cruzando perspectivas e conceitos. Revista Lusófona de Educação. 8(8), 63-83. file://C:/Users/andre/Downloads/691-Texto\%20do\%20artigo-2485-1-10-20090721.pdf

Santos, L. F., Campos, M. L. I. L, Lacerda, C. B. F., \& Goes, A. M.(2015). Desafios tecnológicos para o ensino de libras na educação a distância. Comunicações. 22(3), 203-219. http://dx.doi.org/10.15600/2238-121X/comunicacoes.v22n3p203-219

Schmidt, M. (2011). Nova História Crítica. São Paulo: Nova Geração.

Silva, E. R. A. de S., \& Delfino, J. R. (2016). Reflexão sobre o emprego de estratégias lúdicas no ensino de química para alunos surdos do ensino médio regular. Acta Tecnológica, 11 (2), 87-98. file:///C:/Users/andre/Downloads/412-2212-1-PB\%20(1).pdf

Silva, R.G. (2016). Educação Bilíngue: Ludicidade no ensino de Libras a partir da Educação Infantil. Revista Multidisciplinar Pey Këyo Científico, 1(2), 1-14. http://periodicos.estacio.br/index.php/pkcroraima/article/view/2483/1222 
Research, Society and Development, v. 10, n. 7, e29210716525, 2021

(CC BY 4.0) | ISSN 2525-3409 | DOI: http://dx.doi.org/10.33448/rsd-v10i7.16525

Silveira, K. A., Enumo, S. R. F., \& Rosa, E. M. (2012) Concepções de professores sobre inclusão escolar e interações em ambiente inclusivo: uma revisão da literatura. Revista Brasileira de Educação Especial. 18 (4), 695-708. https://www.scielo.br/pdf/rbee/v18n4/a11v18n4.pdf

Sousa, S. F., \& Silveira, H. E. (2011). Terminologias Químicas em Libras: A Utilização de Sinais na Aprendizagem de Alunos Surdos. Química Nova na Escola. 33(1), 37-46. http://qnesc.sbq.org.br/online/qnesc33_1/06-PE6709.pdf

Stadler, J. P. (2019). Sinalização de termos químicos em libras: necessidade de padronização. Revista Educação Especial em Debate. 4 (7), 81-91. file:///C:/Users/andre/Downloads/26520-Texto\%20do\%20artigo-74990-1-10-20190704\%20(2).pdf

UNESCO (1994). Declaração de Salamanca sobre princípios, política e práticas na área das necessidades educativas especiais. Salamanca. https://pnl2027.gov.pt/np4/\%7B \$clientServletPath\%7D/?newsId=1011\&fileName=Declaracao_Salamanca.pdf 